\title{
Prions: Some Details and Diseases
}

\author{
Saif Jabbar Yasir ${ }^{1}$, Taghreed Abdul Kareem Al- Makhzoomy ${ }^{2}$ \\ ${ }^{1}$ Microbiology, Faculty of Medicine, University of Kufa, Najaf, Iraq \\ ${ }^{2}$ Biology, Faculty of Science, University of Kufa, Najaf, Iraq \\ *e-mail: saif.alshehmani@uokufa.edu.iq ${ }^{1}$, taghrida.zaeerdham@uokufa.edu.iq ${ }^{2}$
}

\begin{abstract}
Prion diseases or transmissible spongiform encephalopathies (TSEs) are a family of rare progressive neurodegenerative disorders that affect both humans and animals. They are distinguished by long incubation periods, characteristic spongiform changes associated with neuronal loss, and a failure to induce inflammatory response. Prion diseases in animals, Scrapie in sheep, chronic wasting disease (CWD) in deer, bovine spongiform encephalopathy (commonly known as "mad cow disease") in cattle, and Creutzfeldt-Jakob disease in humans are all examples of infectious diseases. The prion protein (PrP) was identified in a patient in 2015, and it was previously believed to be the cause of all known mammalian prion diseases. However, The protein alpha-synuclein, which is thought to be responsible for MSA, was suggested to be the cause of the disease in 2015.
\end{abstract}

Keywords: Prions 1, $\operatorname{Pr} P^{C}$ Function 2, $\operatorname{Pr} P^{C}$ Structure 3, Scrapie 4

Article Information
Received: June 25, 2021; Revised: Augest 12, 2021; Online: September 30, 2021

\section{INTRODUCTION}

Prusiner is a term used to describe a tiny proteinaceous infectious particle that is resistant to most nucleic acid inactivation methods . Misfolded proteins known as prions have the capacity to infect healthy individuals when they infect normal versions of the same protein with their misfolded structure. Humans and many other species are affected by a variety of fatal and transmissible neurodegenerative disorders, many of which are defined by the presence of these proteins. [1] Although the origin of normal protein misfolding is unknown, It is believed that the aberrant three-dimensional structure confers infectious characteristics by compressing adjacent protein molecules into the same shape as the defective three-dimensional structure. Although the source of the abnormal three-dimensional structure is unknown, The name "prion" originates from the phrase "proteinaceous infectious particle," which means "proteinaceous infectious particle." Moreover, When compared to other known infectious agents, such as virus-like organisms, bacteria and fungi, and parasites, the hypothesised role of protein as an infectious agent is in stark contrast to the other known infectious agents, which are all made up of nucleic acids and are therefore incompatible with the hypothesis (DNA, RNA, or both). ${ }^{[2][3][4]}$ [5] Prion diseases in animals, such as Creutzfeldt-Jakob disease, are described as illnesses in which there is a change in brain function. In humans, prion diseases are described as illnesses in which there is a change in brain function. Prion diseases in animals, Scrapie in sheep, chronic wasting disease (CWD) in deer, bovine spongiform encephalopathy (commonly known as "mad cow disease") in cattle, and Creutzfeldt-Jakob disease in humans are all examples of infectious diseases. [6]

The prion protein (PrP) was identified in a patient in 2015, and it was previously believed to be the cause of all known mammalian prion diseases. However, The protein alphasynuclein, which is thought to be responsible for MSA, was suggested to be the cause of the disease in 2015. [7] 


\section{History:}

During the 18th and 19th centuries, it was discovered that the shipment of sheep from Spain coincided with the outbreak of a disease known as scrapie. It was found that the affected animals would "lay down, gnaw at their feet and legs, rub their backs against fence posts, fail to flourish, stop eating, and eventually become lame" as a result of this condition. A key characteristic of the disease was also found to have a prolonged incubation period, which is a primary characteristic of transmissible spongiform encephalopathies (TSEs). Despite the fact that the origin of scrapie was unknown at the time, it is widely considered to be the first case of transmissible spongiform encephalopathy to be documented. [8]

\section{History:}

During the 18th and 19th centuries, it was discovered that the shipment of sheep from Spain coincided with the outbreak of a disease known as scrapie. It was found that the affected animals would "lay down, gnaw at their feet and legs, rub their backs against fence posts, fail to flourish, stop eating, and eventually become lame" as a result of this condition. A key characteristic of the disease was also found to have a prolonged incubation period, which is a primary characteristic of transmissible spongiform encephalopathies (TSEs).Despite the fact that the origin of scrapie was unknown at the time, it is widely considered to be the first case of transmissible spongiform encephalopathy to be documented. [8]

The work of Carleton Gajdusek, who began his research in the 1950s and was eventually successful in demonstrating that the kuru virus could be transmitted to chimpanzees through the use of what was considered to be a unique infectious agent, led to his being awarded the Nobel Prize in 1976 for his work.. It was during the 1960s that they came up with the notion that the transmissible spongiform encephalopathies are caused by an infectious agent that is totally made of proteins. They were both working in London at the time of their discovery., which they named the "protein hypothesis." Tikvah Alper, a radiation biologist, and John Stanley Griffith, a biophysicist, were both working in London when they came up with this hypothesis. " [9][10].
Field's pioneering research on scrapie and kuru showed evidence for the transmission of pathologically inactive polysaccharides, which only become infectious after being transmitted to a new host, according to his results. [11] After discovering that a mysterious infectious agent causing the diseases scrapie and CreutzfeldtJakob disease was resistant to ionizing radiation, Alper and Griffith embarked on an investigation to determine why this was the case. Their findings led them to the discovery that the agent was a virus.. [12] Alper and Griffith sought to come up with a plausible explanation for why this was happening. [13] In the opinion of Griffith, there are three ways in which a protein might act as a pathogen: [14]

In the case where the protein is produced by a normally suppressed gene and the protein's introduction has the ability to induce the gene's expression, thereby reawakening the dormant gene, the result would be a process indistinguishable from replication, because the gene's expression would produce the protein, which in turn would wake up the gene in other cells, as previously stated.

According to his second hypothesis, which serves as the foundation for contemporary prion theory, an abnormal form of a cellular protein could cause normal proteins of a similar kind to be converted into the abnormal form, resulting in the spread of the disease. This hypothesis was later proven correct. According to his third hypothesis, the agent might be an antibody if the antibody was directed against the agency's own target antigen, because an antibody directed against the agent would result in an increase in the quantity of antibody produced against the agent. Because there was no obvious immunological response in the research, Griffith, on the other hand, understood that this third explanation was unlikely to be accurate as well. [15]

When publishing the second edition of his "Central dogma of molecular biology," Francis Crick (1970) accepted the possibility that the Griffith protein-only hypothesis may be relevant for scrapie propagation: " A probable conflict between Griffith's concept and his own was noticed by him notwithstanding his claim that sequence information cannot be transferred from one protein to another or from one protein to either RNA or DNA (although it was not so 
promoted by Griffith). [16] It was eventually determined that the revised hypothesis was correct, with reverse transcription serving as one of the critical components As Howard Temin and David Baltimore found in 1970, there is a relationship between the two. [17]

A potential infectious protein that did not appear to be present in healthy hosts was discovered by Stanley Prusiner of the University of California, San Francisco in 1982, according to his team., but it took them two years to isolate the protein following Prusiner's announcement. [18] "Proteinacious infectious particle" (prion) is the name given to the protein, which is a combination of the words protein and infection A popular theory when the prion was initially identified was that the protein was the result of a usually quiet gene. The identical protein does exist in normal hosts, albeit in a different form, as was later revealed. [19]

However, when researchers found identical proteins in unaffected people, Griffith's second hypothesis - that a mutant version of the host protein may convert other proteins of the same kind into mutant forms-became widely accepted as a viable explanation. [clarification needed] There is a particular protein called the prion protein $(\mathrm{PrP})$ that is made up of the prion protein itself (PrP) (PrP). [15] For discovering prions in the 1960s, Prusiner was awarded the Nobel Prize in Physiology or Medicine in 1997 for his work.. [20]

\section{Structure:}

The glycosylphosphatidylinositol molecule attaches the prion protein (PrPC), a membrane protein that is very conserved, to the membrane. Serine 231 on PrPC's C-terminus has a GPI anchor attached, which results in the production of an amino acid protein of 209 amino acids before it can be transported to the cell's outer membrane. The PrPC signal peptide's Nterminus is cleaved. PrP attaches to lipid rafts on the cell surface and is cycled back and forth between the endocytic compartment and the internalized protein compartment around every 60 minutes after that. [21].

Researchers have discovered that PrPC has a four-octapeptide repeat domain at its unstructured N-terminus, as well as an extraglobular C-terminal domain that has two antiparallel sheet topologies and three helixes.
Prion isoforms with hydrophobic regions between amino acids 113 and 135 may have a transmembrane domain. When it comes to Nglycosylation, cysteines 179 and 214 have just one disulfide bond whereas asparagines 182 and 198 have two. [22].

As expected with 90 percent sequence homology [m90], studies of prion structural features across species reveal striking similarities, however, between -helix 2 and the connecting -strand, which is found only in Cervid. Other species' versions of this area are flexible and disorganized. In cervids, the loop is stiff because of an S170N and N174T amino acid change [23], according to further research. The vulnerability of a species to PrPSc has been linked to structural variations in PrPC. This suggests that cervid PrP's stiff loop structure contributes to the fast horizontal transmission of CWD [23].

Various conformations in the otherwise highly conserved NMR structures of cell prion proteins (PrPC) from different mammals, including species differences in a surface epitope consisting of the loop connecting the second helix of the second-strand, are in a state of dynamic equilibrium with respect to one another in the NMR structures.2. Changing Tyr169 in mouse PrPC to Ala or Gly removes the local dynamic conformational polymorphism, while changing Tyr 169 back to Phe leaves it in. NMR structure analyses of mouse $\operatorname{PrP}(121-231)$ at $20{ }^{\circ} \mathrm{C}$ and wild-type $\mathrm{mPrP}(121-231)$ at $37{ }^{\circ} \mathrm{C}$ were used to identify the two limiting structures involved in this local conformational exchange in wild-type mouse PrPC, as well as analyses of exchange effects on NMR signals.

This demonstrated the significant differences in solvent-exposed epitopes at the 22 loop between the two exchange structures. As a result of the structural information revealed in this study, further studies using transgenic laboratory animals are now possible in an effort to discover the physiological role of the cell's prion protein, which has remained a mystery up until now. (24) 


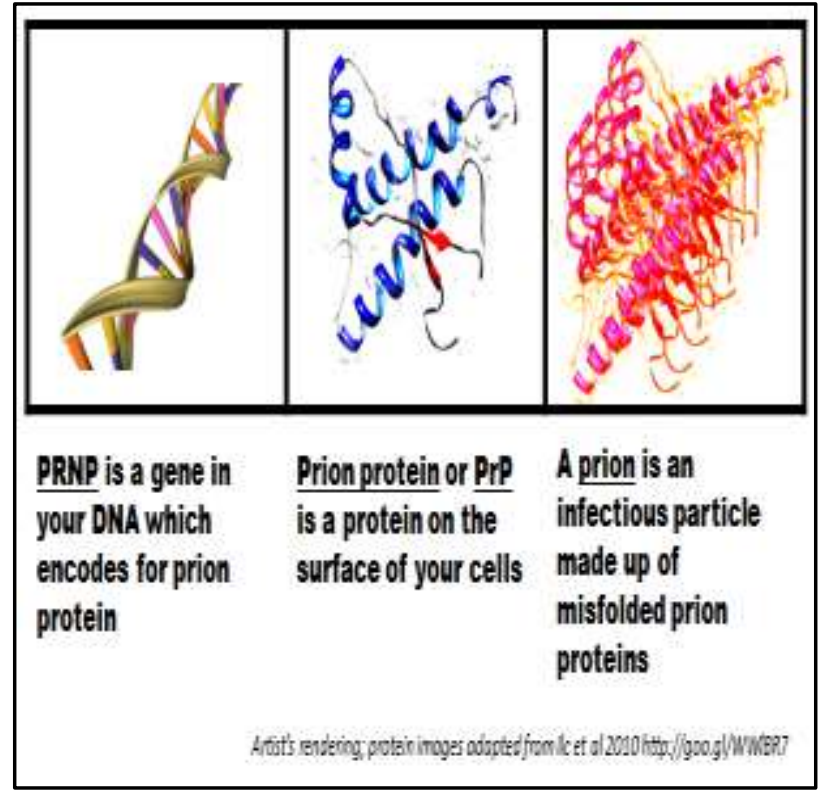

http://www.prionalliance.org/wpcontent/upl oads/2013/11/prnp-prp-prion.png [117]

\section{$\operatorname{PrP}^{\mathrm{C}}$ Function}

The function of PrPC is unknown despite the fact that it has a highly conserved sequence across species and that it is found everywhere in the body. It has been suggested that PrPC is engaged in a variety of activities, including copper metabolism [m91, 92]; neuroprotective function $(25,26]$; synapse formation/function [27]; and neuritogenesis [28].

In all species, copper serves a crucial physiological function as a cofactor in a variety of activities including as oxidative stress protection, blood coagulation, cell growth and development, respiration, and iron transport. Copper is essential for all of these functions. [29]. For the sake of survival and growth, copper is necessary by all living organisms. Menkes syndrome is a kind of neurological disorder. [30] Additionally, Alzheimer's disease (AD), amyotrophic lateral sclerosis [ALS], and Parkinsonism are all examples of neurodegenerative illnesses.as well as being transferable It has been proven that copper deficiency in humans causes pongiform encephalopathy (TSE), one of the most dangerous diseases (TSEs) [31]. The histidinecontaining octapeptide repeat region of the PrPC protein has been shown in several experiments to be capable of binding up to four $\mathrm{Cu} 2+$ ions. [32].
$\mathrm{Cu}$ ions cause a change in PrPC's conformational state. So you have structures with attributes like enhanced protease resistance and the capacity to assemble [33] that are comparable to those of an infected conformation, but the structures are different from those of an infected conformation. Micromolar copper concentrations have also been found to trigger cell-surface PrPC [34] endocytosis. Therefore, it has been postulated that PrPC functions in copper absorption and efflux, as well as functioning as a copper reservoir at the cell's surface that does not induce endocytosis, as well. [35].

\section{Diseases:}

Proteopathy, or the disease caused by structurally defective proteins, is what prion disease is. CJD and vCJD, as well as GSS, FFI, and kuru are all considered to be caused by prions.As a result of evidence suggesting prions are involved in the course of Alzheimer's, Parkinson's, and ALS, these diseases have been called prion-like disorders. [36] [37] [38] [39] Prionogenic characteristics have been found in several yeast proteins. [40] [41] It's possible that prion replication, like other forms of replication, may be altered by epimutation or natural selection. [42]

Around $85 \%$ of all human instances of prion disease, which typically manifests as dementia and myoclonus, are caused by Creutzfeldt-Jakob disease. Prion disorders caused by viruses or genetic mutations account for the remaining $85 \%$ of cases. All of these illnesses are caused by mutations in the prion protein gene (PRNP), which is passed down solely via females. GSS and deadly familial insomnia are a few examples of these illnesses. $(43,44,45,46)$ Studies indicating the spread of disease through brain filtrates from sick family members were wrongly attributed to viruses by researchers who misunderstood their findings $(47,48)$. There is no virus that causes Creutzfeldt-Jakob disease, and mutations in the protein that makes prion proteins cause familial prion disorders (49).

Cellular prion protein (PrPC) has recently been discovered to be an A oligomer receptor on its cell surface. PrPC is a glycoprotein found on the cell surface that aids in the spread of prions, proteinaceous infectious pathogens that 
multiply by imposing an aberrant shape on PrPC molecules. A oligomers in Alzheimer's disease (AD) cause synapse failure and cognitive impairment by transducing neurotoxic signals. Aggregated A or tau has been proven to have prion-like activity, which might allow it to spread throughout the brain, as more and more research is being done. Recent studies on the function of $\mathrm{PrPC}$ and its involvement in AD are reviewed in this article, and possible therapeutic implications of PrPC-based methods in the treatment of $\mathrm{AD}$ are discussed.

Because PrPC is involved in the transmission of Amyloid-oligomer-induced synaptic dysfunction, it is possible that medicines that target PrPC specifically will have therapeutic benefit in the treatment of Alzheimer's. A deadly degenerative brain disorder known as Creutzfeldt-Jakob disease, subacute spongiform encephalopathy (SSE) or neurocognitive impairment caused by prion disease is also known as Creutzfeldt-Jakob disease. It is caused by prion disease and affects the central nervous system (CJD). [52] [53] Memory difficulties, behavioral abnormalities, sluggishness, and vision impairments are some of the early signs.

Dementia, uncontrollable movements, blindness, weakness, and coma are some of the later signs. [52] Around $70 \%$ of those who are diagnosed with cancer die within a year of being diagnosed. Following the discovery of the illness in 1922 by Walther Spielmeyer, it was named after two German neurologists, Hans Gerhard Creutzfeldt and Alfons Maria Jakob, and the disorder became known as CreutzfeldtJakob disease as a result of their work. [53].

Following the discovery of the illness by Walther Spielmeyer in 1922, it was named after two German neurologists, Hans Gerhard Creutzfeldt and Alfons Maria Jakob, and the disorder became known as Creutzfeldt-Jakob disease as a result of their work. [52] [53] When the virus is introduced to the brain or spinal tissue of an infected individual, the virus has the ability to spread. [52] However, despite the likelihood of transmission in some forms of Creutzfeldt-Jakob disease, there is no evidence that sporadic CJD may be spread by frequent contact or blood transfusions in the general population. [54] [55] To arrive at a diagnosis, it is necessary to rule out all other plausible explanations. Diagnostic tests such as magnetic resonance imaging (MRI), electroencephalograms, and spinal taps may be used to assist confirm the diagnosis. [52]

When CJD initially manifests itself, it is generally in the form of quickly progressing dementia, which can include memory loss, personality abnormalities, and hallucinations. Myoclonus (jerky movements) is usually present in 90 percent of patients, however it may be missing at the time of start in certain cases. [56] There are a variety of additional symptoms that are frequently noticed in patients, including anxiety, depression, paranoia, obsessivecompulsive symptoms, and psychosis.. ${ }^{[57] .}$

Physical symptoms include slurred speech, ataxia (balance and coordination disorder), altered walking, and stiff posture. Most patients with CJD also have involuntary movements to go along with their symptoms. The illness can last months or even weeks depending on the individual, but random (non-inherited) CJD can be deadly within weeks. ${ }^{[58]}$ The majority of patients die six months following the onset of symptoms, frequently from pneumonia as a result of weakened coughing reflexes. Approximately $15 \%$ of patients with CJD live for two or more years after diagnosis. ${ }^{[59]}$

Memory loss, personality changes, and hallucinations-all of which are hallmarks of Alzheimer's disease-are prevalent in the early stages of CJD, as are other indications of the condition. In $90 \%$ of instances, myoclonus (jerky movements) is present, however it may not be present at the time of the initial start. [56] Anxiety, sadness, paranoia, OCD, and psychosis are all common side effects of schizophrenia. [57] Physical symptoms include slurred speech, ataxia (balance and coordination disorder), altered walking, and stiff posture. Uncontrollable movements are common in persons who have CJD. It can take months or even weeks for sporadic (non-inherited) CJD to kill a person. [58] Coughing reflexes are compromised as a result of most patients dying six months after first experiencing symptoms. CJD patients have a five-year survival rate of about $15 \%$. [59]

As the brain's nerve cells die off, aberrant prion proteins accumulate, causing symptoms such as dementia and other cognitive problems. Under a microscope, the brain tissue of a CJD 
patient displays several tiny holes, which were previously occupied by sick nerve cells and are now free of them. When the prion infects the brain, parts of the brain may seem like sponges. [60]Fatal insomnia is a rare hereditary disease that manifests as a persistent inability to fall asleep and is fatal if left untreated.(61)

[62] Sleeping difficulties usually develop slowly and worsen with time.. [63] Speech difficulties, balance issues, and dementia are all possible side effects. [64]. It's fatal within a few months to a few years after exposure [65]

It's a brain prion disease. The gene that codes for the protein PrPC is frequently mutated to cause it. [62] When the damaged nerve cells are removed from the brain tissue of a CJD patient, numerous tiny holes appear. Sleep studies, PET scans and genetic tests are used to confirm the diagnosis, especially if the patient comes from a family with the condition. A postmortem brain autopsy is required to confirm the diagnosis, as with other prion disorders. [61]

There is no known treatment for fatal insomnia, which causes hallucinations, delirium, confusional states similar to dementia, and finally death as a result of gradually deteriorating insomnia. [66] After the first signs and symptoms appear, patients have an average survival period of 18 months. In 1765, an Italian man died in Venice as the first documented case of the disease. [67]

Fore people of Papua New Guinea are suffering from Kuru, a neurological illness that impairs their brain function. It is a rare, incurable, and lethal disease. Kuru is caused by the transmission of incorrectly folded proteins (prions), which shows itself as symptoms such as tremors and a loss of coordination as a result of neurodegenerative changes. The term "kuru" is considered to derive from the Greek words "kuria" or "guria," which mean "to shake."

Kru means "shaking" or "trembling," depending on how you look at it. [68] Because of the disease's pathological bouts of laughter, it's also known as the "laughing sickness." The Fore tribe of Papua New Guinea was once thought to have acquired Kuru through funeral cannibalism, but this has now been proven without a shadow of a doubt. Cooking and eating the bodies of deceased family members was considered a way to release the spirits of the dead. [69] Women and children were the most common consumers of the brain, which had the highest concentration of infectious prions, making it an ideal vehicle for the spread of kuru. As a result, women and children were more likely to contract the illness.

The outbreak began when a villager died of Creutzfeldt-Jakob disease, which had appeared to be sporadic in that person. Locals got the sickness after eating the contaminated brain, and the disease subsequently spread to others when they ate their infected brains. [70,72]. In the early 1960 s, endocannibalism was considered as a possible source of kuru's transmission, but the illness persisted due to kuru's long incubation period, which might last anywhere from 10 to 50 years. $(73,74]$.

As of 2010, there have been no reported cases of kuru, with sources differing on when the last recorded victim died. The pandemic peaked in 1957, with 200 deaths per year, and has been steadily declining since. [75] [76] [77]

\section{Transmission :}

There are three ways prion illnesses can arise: acquired, familial, or sporadic, according to research findings. [78] A common misconception is that the sick form causes structural changes in the healthy form by interacting with it directly. PrPC to PrPSc conversion is made possible, according to one theory, by an as yet undiscovered cellular protein (Protein X) that brings two molecules of each molecule together to form one large, multimolecular complex. [79]

Animals are most commonly affected by eating tainted food. In the event that prions get up in the environment, it is possible that animal waste or body fluids like urine or saliva might introduce them. Due of their affinity for clay and other minerals, they may stay in the soil for an extended length of time. [80]

There is evidence that infection can arise via prions in manure, according to researchers at the University of California. [81] It's possible that the disease might spread far and wide due to the prevalence of manure around water reservoirs and its usage on a large number of crop fields. According to a study on scrapie infection in laboratory mice conducted by researchers in January 2011, prions spread via aerosol transmission on aerosol particles. [82] A preliminary study released in 2011 found a 
relationship between the usage of urine-derived human menopausal gonadotropin to treat infertility and the spread of prions.

When it comes to proteins, There are several studies on the prion protein, which is prevalent in healthy mammalian beings and is known as PrPC in its cellular form. When it comes to knowing how transmissible spongiform encephalopathies (TSE) $(83,84,85)$ cause brain degeneration by participating in molecular pathways, progress has been achieved. However, many issues remain unresolved.

Molecular architecture of the recombinant mouse prion protein $(86,87)$ matches that of healthy animals' PrPC protein component, according to the NMR solution structure (88). This PrP has three -helices at the N-terminus, a brief antiparallel two-stranded sheet at the Cterminus, and residues 229-231 at the Cterminus. According to Schätzl et al. (89), The numbering of PrPs from different species vary very little from one another (88). There is no difference in the NMR structures of recombinant PrPs from various mammalian species other than the presence of a surface epitope, which is formed in part by a loop of residues 166-172 connecting strand/helix 2 with helix 2. $(90,91,92,93)$.

The presence of a number of amino acid swaps across mammals in this polypeptide segment and its immediate surroundings should be noticed $(94,95,96)$, in contrast to the generally strong sequence conservation seen in the globular domain of mammalian PrPs, which should also be acknowledged. (94). The NMR structures of several mammalian prion proteins were shown to be physically disordered at 20 degrees Celsius. When compared to other species at similar temperatures $(97,98)$, the NMR structures of PrPC have been determined to be well-defined and free of structural disorder.

According to test findings, a blood transfusion may have transmitted this disease. Pre-existing dietary exposure to a BSE agent may have contributed to the recipient's illness. As a result, the patient's age was significantly older than that of most CJD cases, and the likelihood of discovering an unrelated case of vCJD in a recipient in the absence of an infection transmitted by a blood transfusion is around 1 in 15000 to 1 in 30000 .(v)

A noninvasive method for detecting prion diseases at an early stage of development may be developed as a result of these results, as this is the first time that PrPSc has been found biochemically in blood. (99)

Considering that the prion protein is encoded by the host's DNA, the question remains as to what drives the prion to become more efficient in destroying its parent. We're stuck with informed assumptions for the time being. Because evolutionary pressure is less effective in the post-reproductive age of the organism, proteins like PrP may have evolved as "messenger" proteins that had both physiologic and malignant potential, but were not chosen against. [100] Yeast might benefit from a "prion-like" event involving Sup35 if it develops in an environment with shifting environmental circumstances, according to the study's authors.

PrP/PrPSc may have evolved from an ancient pathogen that was integrated into the host's genome and exploited for its helpful properties while its pathogenic potential was maintained at an absolute minimum, according to another hypothesis. The natural tendency of proteins to acquire a -sheet-rich shape might induce Prion illness in animals, or to put it another way [101], Failure of the organism to prevent their production and accumulation in some instances, and the coincidental capacity of the conformational isomer to enter organisms and cells through natural portals.

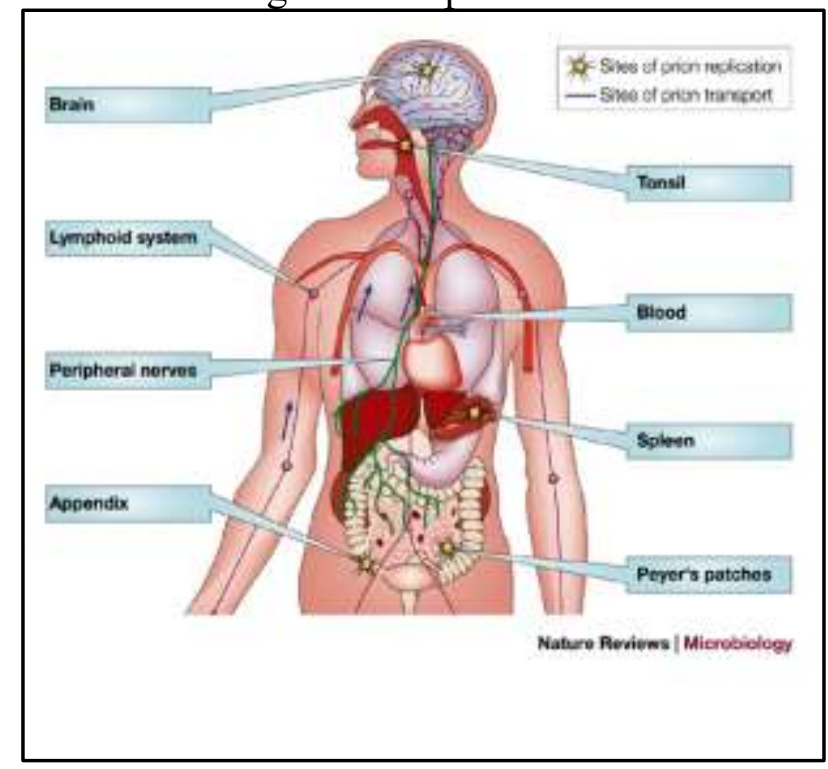

Nature Reviews Microbiology [118] 


\section{Scrapie}

Scrapie is probably definitely a disease that has existed for thousands of years. According to some sources, scrapie has been described as far back as the Roman era [102], while others believe that scrapie has been described as far back as the ancient Greeks. The name "scrapie" was first used in a paper published in 1750, but at the time, the term "distemper" was more commonly used to describe the condition [103]. Farmers, shepherds, and government officials, not scientists or veterinarians, contributed the great majority of the written reports. These people worked closely with infected animals to preserve their financial and economic interests, and they went to great efforts to keep epidemics under wraps. [104].

Recognition of a scrapie-infected animal resulted in the culling of the whole herd and the quarantining of grazing space for an extended period of time [105], which was similar to contemporary management practices. This conduct indicated a thorough understanding of scrapie as an infectious disease.

The symptoms of scrapie were accurately described in the past, but the concept of what caused the condition differed significantly. There are several theories as to why thunder is a contributing factor, including severe weather, nutritional inadequacy, parasites, humidity, tail docking, and the age at which the sheep are married. Other theories include cross-breeding and inbreeding. A similar amount of discussion took place over the mode of transmission itself, Various hypotheses, ranging from sexual transmission to chance occurrence to genetic inheritance, are being advanced and tested. A French study in 1936 found that using scrapieinfected sheep brain and spinal cord suspensions, scientists were able to infect sheep and goats, resulting in scrapie infection of the sheep and goats' brain, eyes, and skin, after more than a century of fruitless attempts to show scrapie transmissibility experimentally.

\section{Diagnosis}

It's been difficult in the past to test for CJD since the early symptoms are so vague, and collecting brain tissue for confirmation is so dangerous. When a person has fast advancing dementia, the diagnosis may be considered, especially if they have the typical medical symptoms such as involuntary muscular jerking, [106] Visual anomalies, as well as issues with coordination/balance and walking, are common. [107] Additional testing may be required to confirm the diagnosis and include the following tests:

A generalized periodic sharp wave pattern may be observed in electroencephalography. In the final phases of sporadic CJD, around half of individuals affected experience periodic sharp wave complexes. [108]. It is possible that finding elevated amounts of the 14-3-3 protein in CSF will aid in the identification of SCJD. A result of a test being positive, on the other hand, should not be taken as proof of a diagnosis. [109] [110] [11] CJD patients' CSF samples were tested for PrPSc using the RT-QuIC assay. It has been shown to be diagnostically sensitive in the 80 percentile and specific in the 100 percentile. [112] Because of this, it is recommended as a highly effective diagnostic tool for detecting illness. [113][114].

T2-weighted MRI of the brain: In T2weighted images, the caudate nucleus and putamen are frequently shown to have strong signal intensity bilaterally.

Neuron-specific enolase (NSE) has been found in recent research to be high in CJD patients. However, its diagnostic value is observed only when coupled with testing for the 14-3-3 protein, which is also elevated in CJD cases. [115] As of 2010, no screening technologies exist to identify infected asymptomatic individuals, such as blood donors, despite advances in research and development. [116]

\section{CONCLUSION}

The function of PrPC is unknown despite the fact that it has a highly conserved sequence across species and that it is found everywhere in the body. It has been suggested that PrPC is engaged in a variety of activities, including copper metabolism, neuroprotective function synapse formation/function and neuritogenesis. 


\section{REFERENCES}

"Prion diseases". Diseases and conditions. National Institute of Health.

"Prion diseases". United States Centers for Disease Control and Prevention. 2019-0503.

"What Is a Prion?". Scientific American. Retrieved 15 May 2018.

"Prion infectious agent". Encyclopaedia Britannica. Retrieved 15 May 2018.

Prusiner SB (June 1991). "Molecular biology of prion diseases". Science. 252 (5012): 1515-22.

Prusiner SB November 1998). "Prions". Proceedings of the National Academy of Sciences of the United States of America. 95 (23): 1336383.

Prusiner SB, Woerman AL, Mordes DA, Watts JC, Rampersaud R, Berry DB, Patel S, Oehler A, Lowe JK, Kravitz SN, Geschwind DH, Glidden DV, Halliday GM, Middleton LT, Gentleman SM, Grinberg LT, Giles K (September 2015). "Evidence for $\alpha$-synuclein prions causing multiple system atrophy in humans with parkinsonism". Proceedings of the National Academy of Sciences of the United States of America. 112 (38): E5308

"How Prions Came to Be: A Brief History Infectious Disease: Superbugs, Science, \& Society". Retrieved 2021-09-17.

Alper T, Cramp WA, Haig DA, Clarke MC (May 1967). "Does the agent of scrapie replicate without nucleic acid?". Nature. 214 (5090): 764-66.

Griffith JS (September 1967). "Self-replication and scrapie". Nature. 215 (5105): 1043-44.

Field EJ (September 1966). "Transmission experiments with multiple sclerosis: an interim report". British Medical Journal. 2 (5513): 564-65.

Adams DH, Field EJ (September 1968). "The infective process in scrapie". Lancet. 2 (7570): 714-16.

Field EJ, Farmer F, Caspary EA, Joyce G (April 1969). "Susceptibility of scrapie agent to ionizing radiation". Nature. 5188. 222 (5188):

90-91.

Bibcode:1969Natur.222...90F.

doi:10.1038/222090a0. PMID 4975649. S2CID 4195610.

Griffith JS (Sep 1967). "Self-replication and scrapie". Nature. 215 (5105): 1043-44.

Bolton D (January 1, 2004). "Prions, the Protein Hypothesis, and Scientific Revolutions". In Nunnally BK, Krull IS (eds.). Prions and Mad Cow Disease. Marcel Dekker. pp. 2160. ISBN 978-0-203-91297-3 - via ResearchGate.

Crick F (August 1970). "Central dogma of molecular biology". Nature. 227 (5258): 561-63.

Coffin JM, Fan H (September 2016). "The Discovery of Reverse Transcriptase". Annual Review of Virology. 3 (1): 29-51.

Taubes G (December 1986). "The game of name is fame. But is it science?". Discover. 7 (12): $28-41$.

Atkinson CJ, Zhang K, Munn AL, Wiegmans A, Wei MQ (2016). "Prion protein scrapie and the normal cellular prion protein". Prion. 10 (1): 63-82.

"The Nobel Prize in Physiology or Medicine, 1997". NobelPrize.org. Retrieved 2010-0228. The Nobel Prize in Physiology or Medicine 1997 was awarded to Stanley B. Prusiner 'for his discovery of Prions - a new biological principle of infection.'

S. L. Shyng, M. T. Huber, and D. A. Harris, "A prion protein cycles between the cell surface and an endocytic compartment in 
cultured neuroblastoma cells," Journal of Biological Chemistry, vol. 268, no. 21, pp. 15922-15928, 1993.

R. Cappai and S. J. Collins, "Structural biology of prions," Contributions to Microbiology, vol. 11, pp. 14-32, 2004.

C. J. Sigurdson and A. Aguzzi, "Chronic wasting disease," Biochimica et Biophysica Acta, vol. 1772, no. 6, pp. 610-618, 2007.

Fred F. Damberger, Barbara Christen, Daniel R. Pérez, Simone Hornemann, and Kurt Wüthrich. Cellular prion protein conformation and function .2011. PNAS 108 (42) 17308-17313;

C. A. Koch, D. Anderson, M. F. Moran, C. Ellis, and T. Pawson, "SH2 and $\mathrm{SH} 3$ domains: elements that control interactions of cytoplasmic signaling proteins," Science, vol. 252, no. 5006, pp. 668-674, 1991.

S. Mouillet-Richard, M. Ermonval, C. Chebassier et al., "Signal transduction through prion protein," Science, vol. 289, no. 5486, pp. 1925-1928, 2000.

A. Aguzzi, F. Baumann, and J. Bremer, "The prion's elusive reason for being," Annual Review of Neuroscience, vol. 31, pp. 439477, 2008.

96m.E. Graner, A. F. Mercadante, S. M. Zanata et al., "Cellular prion protein binds laminin and mediates neuritogenesis," Molecular Brain Research, vol. 76, no. 1, pp. 85-92, 2000.

S. Puig and D. J. Thiele, "Molecular mechanisms of copper uptake and distribution," Current Opinion in Chemical Biology, vol. 6, no. 2, pp. 171-180, 2002.

M. D. Harrison and C. T. Dameron, "Molecular mechanisms of copper metabolism and the role of the menkes disease protein," Journal of Biochemical and Molecular Toxicology, vol. 13, no. 2, pp. 93-106, 1999.

D. J. Waggoner, T. B. Bartnikas, and J. D. Gitlin, "The role of copper in neurodegenerative disease," Neurobiology of Disease, vol. 6, no. 4, pp. 221-230, 1999.
E. D. Walter, M. Chattopadhyay, and G. L. Millhauser, "The affinity of copper binding to the prion protein octarepeat domain: evidence for negative cooperativity," Biochemistry, vol. 45, no. 43, pp. 13083-13092, 2006.

E. Quaglio, R. Chiesa, and D. A. Harris, "Copper converts the cellular prion protein into a protease-resistant species that is distinct from the scrapie isoform," Journal of Biological Chemistry, vol. 276, no. 14, pp. 11432-11438, 2001.

P. C. Pauly and D. A. Harris, "Copper stimulates endocytosis of the prion protein," Journal of Biological Chemistry, vol. 273, no. 50, pp. 33107-33110, 1998.

L. Westergard, H. M. Christensen, and D. A. Harris, "The cellular prion protein PrPc: its physiological function and role in disease," Biochimica et Biophysica Acta, vol. 1772, no. 6, pp. 629-644, 2007

Laurén J, Gimbel DA, Nygaard HB, Gilbert JW, Strittmatter SM (February 2009). "Cellular prion protein mediates impairment of synaptic plasticity by amyloid-beta oligomers". Nature. 457 (7233): 1128-32.

Olanow CW, Brundin P (2013). "Parkinson's disease and alpha synuclein: is Parkinson's disease a prion-like disorder?". Movement Disorders. 28 (1): 31-40.

Goedert M

(2015).

"NEURODEGENERATION.Alzheimer's and Parkinson's diseases: The prion concept in relation to assembled $A \beta$,tau, and $\alpha$ synuclein". Science. 349 (6248): 1255555.

Lee S, Kim HJ (2015). "Prion-like Mechanism in Amyotrophic Lateral Sclerosis: are Protein Aggregates the Key?". Experimental Neurobiology. 24 (1): $1-7$.

Alberti S, Halfmann R, King O, Kapila A, Lindquist S (2009). "A systematic survey identifies prions and illuminates sequence features of prionogenic proteins". Cell. 137 (1): 146-58. 
Aguzzi A (2008). "Unraveling prion strains with cell biology and organic chemistry". Proceedings of the National Academy of Sciences of the United States of America. 105 (1): 11-12.

Li J, Browning S, Mahal SP, Oelschlegel AM, Weissmann C (February 2010). "Darwinian evolution of prions in cell culture". Science. 327 (5967): 869-72.

Hsiao K, Baker HF, Crow TJ, et al. Linkage of a prion protein missense variant to Gerstmann-Sträussler

syndrome. Nature 1989;338:342-345

Dlouhy SR, Hsiao K, Farlow MR, et al. Linkage of the Indiana kindred of GerstmannSträussler-Scheinker disease to the prion protein gene. Nat Genet 1992;1:64-67

Petersen RB, Tabaton M, Berg L, et al. Analysis of the prion protein gene in thalamic dementia. Neurology 1992;42:1859-1863

Poulter M, Baker HF, Frith CD, et al. Inherited prion disease with 144 base pair gene insertion. 1. Genealogical and molecular studies. Brain 1992;115:675-685

Gabizon R, Rosenmann H, Meiner Z, et al. Mutation and polymorphism of the prion protein gene in Libyan Jews with Creutzfeldt-Jakob disease (CJD). Am J Hum Genet 1993;53:828-835

Roos R, Gajdusek DC, Gibbs CJ Jr. The clinical characteristics of transmissible CreutzfeldtJakob disease. Brain 1973;96:1-20

Masters CL, Gajdusek DC, Gibbs CJ Jr. Creutzfeldt-Jakob disease virus isolations from the Gerstmann-Sträussler syndrome with an analysis of the various forms of amyloid plaque deposition in the virusinduced spongiform encephalopathies. Brain 1981;104:559-588

Hsiao K, Doh-ura K, Kitamoto T, Tateishi J, Prusiner SB. A prion protein amino acid substitution in ataxic Gerstmann-Sträussler syndrome. Ann Neurol 1989;26:137137 abstract.
"Creutzfeldt-Jakob Disease Fact Sheet National Institute of Neurological Disorders and Stroke". NINDS. March 2003. Archived from the original on 4 July 2017.

"Creutzfeldt-Jakob Disease, Classic (CJD)". CDC. 2 October 2018. Manix, Marc; Kalakoti, Piyush; Henry, Miriam; Thakur, Jai; Menger, Richard; Guthikonda, Bharat; Nanda, Anil (2015-1101). "Creutzfeldt-Jakob disease: updated diagnostic criteria, treatment algorithm, and the utility of brain biopsy". Neurosurgical Focus. 39 (5): E2.

Brandel J, Vlaciu M, Culeux A, Belondrade M, Grznarova K, Plu I, Levasseur M, Haik S (July 2, 2020). "Variant Creutzfeldt-Jakob Disease Diagnosed 7.5 Years after Occupational Exposure". New England Journal of Medicine. 383 (1): 83-85.

"Transfusion Handbook/ 5.4: Variant Creutzfeldt-Jakob disease (vCJD)". Joint United Kingdom (UK) Blood Transfusion and Tissue Transplantation Services Professional Advisory Committee. 4 February 2014.

"A 49-Year-Old Man With Forgetfulness and Gait Impairment".17. Archived from the original on 20-07-06.

Murray ED, Buttner N, Price BH. (2012) Depression and Psychosis in Neurological Practice. In: Neurology in Clinical Practice, 6th Edition. Bradley WG, Daroff RB, Fenichel GM, Jankovic J (eds.) Butterworth Heinemann. April 12, 2012.

Brown P, Cathala F, Castaigne P, Gajdusek DC (November 1986). "Creutzfeldt-Jakob disease: clinical analysis of a consecutive series of 230 neuropathologically verified cases". Annals of Neurology. 20 (5): 597602.

Gambetti, Pierluigi. "Creutzfeldt-Jakob Disease (CJD)". The Merck Manuals: Online 
Library. 2011.Archived from the original on 2011-06-04.

Atalay, Fatma Oz; Tolunay, Sahsine; Ozgun, Gonca; Bekar, Ahmet; Zarifoglu, Mehmet (2013). "Creutzfeldt-jakob disease: report of four cases and review of the literature". Turkish Journal of Pathology. 31 (2): 148-152.

"Fatal familial insomnia". 2019. Genetic and Rare Diseases Information Center (GARD) - an NCATS Program.

$\begin{array}{lr}\text { "Fatal Insomnia } & \text { Neurologic } \\ \text { Disorders". 2019.Merck } & \text { Manuals } \\ \text { Professional Edition. } & \end{array}$

"Fatal Familial Insomnia". 2019. NORD (National Organization for Rare Disorders). "What is fatal familial insomnia?". Healthline. 26 January 2018.

"Fatal Insomnia". Merck Manual. Retrieved 4 May 2018.

Schenkein J, Montagna P (2006). "Self management of fatal familial insomnia. Part 1: what is FFI?". MedGenMed. 8 (3): 65.

Max, D. T. (2007). The Family that Couldn't Sleep: A medical mystery. New York: Random House Trade Paperbacks. p. $\underline{4}$.

"The epidemiology of kuru in the period 1987 to 1995", 2019.Department of Health (Australia).

Hoskin, J.O.; Kiloh, L.G.; Cawte, J.E. (1969). "Epilepsy and guria: The shaking syndromes of New Guinea". Social Science \& Medicine. 3 (1): 39-48.

Scott, Graham (1978). The Fore Language of Papua New Guinea. Pacific Linguistics. pp. 2, 6 .

Whitfield, Jerome T; Pako, Wandagi H; Collinge, John; Alpers, Michael P (2008). "Mortuary rites of the South Fore and kuru". Philosophical Transactions of the Royal Society B: Biological Sciences. 363 (1510): 3721-3724.

Bichell, Rae Ellen (2016). "When People Ate People, A Strange Disease
Emerged". NPR.org. Retrieved 2018-0408.

"Kuru". MedlinePlus Medical Encyclopedia. Retrieved 2016-11-14.

Alpers, MP (2007). "A history of kuru". Papua and New Guinea Medical Journal. 50 (12): 10-9.

Rense, Sarah (2016). "Here's What Happens to Your Body When You Eat Human Meat". Esquire.

A life of determination". Monash University Faculty of Medicine, Nursing and Health Sciences. 2009-02-23. Archived from the original on 2015-12-10.

Collinge, John; Whitfield, Jerome; McKintosh, Edward; Beck, John; Mead, Simon; Thomas, Dafydd J; Alpers, Michael P (2006). "Kuru in the $21 \mathrm{st}$ century-an acquired human prion disease with very long incubation periods". The Lancet. 367 (9528): 2068-2074.

Telling GC, Scott M, Mastrianni J, Gabizon R, Torchia M, Cohen FE, DeArmond SJ, Prusiner SB (1995). "Prion propagation in mice expressing human and chimeric PrP transgenes implicates the interaction of cellular PrP with another protein". Cell. 83 (1): 79-90.

Johnson CJ, Pedersen JA, Chappell RJ, McKenzie D, Aiken JM (2007). "Oral transmissibility of prion disease is enhanced by binding to soil particles". PLOS Pathogens. 3 (7): e93

Tamgüney G, Miller MW, Wolfe LL, Sirochman TM, Glidden DV, Palmer C, Lemus A, DeArmond SJ, Prusiner SB (September 2009). "Asymptomatic deer excrete infectious prions in faeces". Nature. 461 (7263): 529-32.

Haybaeck J, Heikenwalder M, Klevenz B, Schwarz P, Margalith I, Bridel C, Mertz K, Zirdum E, Petsch B, Fuchs TJ, Stitz L, Aguzzi A (2011). "Aerosols transmit prions to immunocompetent and immunodeficient mice". PLOS Pathogens. 7 (1): e1001257. 
Van Dorsselaer A, Carapito C, Delalande F, Schaeffer-Reiss C, Thierse D, Diemer H, McNair DS, Krewski D, Cashman NR (2011). "Detection of prion protein in urinederived injectable fertility products by a targeted proteomic approach". PLOS ONE. 6 (3): e17815.

Westergard L, Christensen HM, Harris DA (20 $07)$ The cellular prion protein $\left(\operatorname{PrP}^{\mathrm{C}}\right)$ : Its physiological function and role in disease. Biochim Biophys Acta 1772:629644.

Aguzzi A, Baumann F, Bremer J (2008) The prion's elusive reason for being. Annu Rev Neurosci 31:439-477.

$\mathrm{a} \_$Linden R, et al. (2008) Physiology of the prion protein. Physiol Rev 88:673-728.

Riek R, et al. (1996) NMR structure of the mouse prion protein domain $\operatorname{PrP}(121-$ 231) Nature 382:180-182.

Riek R, Hornemann S, Wider G, Glockshuber

R, Wüthrich K (1997) NMR

characterization of the full-length recombinant murine prion protein, $\mathrm{mPrP}$ (23-231) FEBS Lett 413:282-288.

Hornemann S, Schorn C, Wüthrich K (2004) N MR structure of the bovine prion protein isolated from healthy calf brains. EMBO Rep 5:1159-1164.

Schätzl HM, Da

Costa M, Taylor L, Cohen FE, Prusiner SB (1995) Prion protein gene variation among primates. J Mol Biol 245:362-374.

James TL, et al. (1997) Solution structure of a 142-residue recombinant prion protein corresponding to the infectious fragment of the scrapie isoform. Proc Natl Acad Sci USA 94:10086-10091.

Zahn R, et al.(2000) NMR solution structure of the human prion protein. Proc Natl Acad Sci USA 97:145-150.

LópezGarcía F, Zahn R, Riek R, Wüthri ch K.(2000) NMR structure of the bovine prion protein. Proc Natl Acad Sci USA 97:8334-8339.
Lysek DA, et al.(2005) Prion protein NMR structures of cats, dogs, pigs, and sheep. Proc Natl Acad Sci USA 102:640645.

Gossert AD, Bonjour S, Lysek DA, Fiorito F, Wüthrich K.(2005) Prion protein NMR structures of elk and of mouse/elk hybrids. Proc Natl Acad Sci USA 102:646650.

Christen B, Pérez DR, Hornemann S, Wüthrich K.(2008) NMR structure of the bank vole prion protein at $20{ }^{\circ} \mathrm{C}$ contains a structured loop of residues 165-171. J Mol Biol 383:306-312.

Christen B, Hornemann S, Damberger FF, Wüt hrich K.(2009) Prion protein NMR structure from tammar wallaby (Macropus eugenii) shows that the $\beta 2-\alpha 2$ loop is modulated by long-range sequence effects. J Mol Biol 389:833-845.

Pérez DR, Damberger FF, Wüthrich K (2010) Horse prion protein NMR structure and comparisons with related variants of the mouse prion protein. J Mol Biol 400:121128.

Wen Y, et al.(2010) Unique structural characteristics of the rabbit prion protein. $\mathrm{J}$ Biol Chem 285:31682-31693.

m. Joaquín Castilla, Paula Saá \& Claudio Soto. Detection of prions in blood. 2005. Nature Medicine volume 11, pages 982-985.

True HL, Lindquist SL. A yeast prion provides a mechanism for genetic variation and phenotypic diversity, Nature, 2000, vol. 407 (pg. 477-83)

Chiti F, Webster P, Taddei N, et al. Designing conditions for in vitro formation of amyloid protofilaments and fibrils, Proc Natl Acad Sci USA, 1999, vol. 96 (pg. 3590-4)

Hope, L. J. Morton, C. F. Farquhar, G. Multhaup, K. Beyreuther, and R. H. Kimberlin, "The major polypeptide of scrapie-associated fibrils (SAF) has the same size, charge distribution and $\mathrm{N}$ - 
terminal protein sequence as predicted for the normal brain protein (PrP)," EMBO Journal, vol. 5, no. 10, pp. 2591-2597, 1986.

R. Riek, S. Hornemann, G. Wider, M. Billeter, R. Glockshuber, and K. Wuthrich, "NMR structure of the mouse prion protein domain $\operatorname{PrP}(121-231)$," Nature, vol. 382, no. 6587, pp. 180-182, 1996.

Y. Bounhar, Y. Zhang, C. G. Goodyer, and A. LeBlanc, "Prion protein protects human neurons against Bax-mediated apoptosis," Journal of Biological Chemistry, vol. 276, no. 42, pp. 3914539149, 2001.

M. Diarra-Mehrpour, S. Arrabal, A. Jalil et al., "Prion protein prevents human breast carcinoma cell line from tumor necrosis factor $\alpha$-induced cell death," Cancer Research, vol. 64, no. 2, pp. 719-727, 2004.

Sattar, Hussain A. (2011). Fundamentals of Pathology. Chicago: Pathoma LLC. p. 187.

Mead S, Rudge P (April 2017). "CJD mimics and chameleons". Practical

Neurology. 17 (2): 113-121.

"Creutzfeldt-Jakob Disease Fact Sheet National Institute of Neurological Disorders and Stroke". www.ninds.nih.gov. Retrieved 2018-01-13.

Satoh J, Kurohara K, Yukitake M, Kuroda Y (1999). "The 14-3-3 protein detectable in the cerebrospinal fluid of patients with prion-unrelated neurological diseases is expressed constitutively in neurons and glial cells in culture". European Neurology. 41 (4): 216-25.

Geschwind MD, Martindale J, Miller D, DeArmond SJ, Uyehara-Lock J, Gaskin D, Kramer JH, Barbaro NM, Miller BL (2003). "Challenging the clinical utility of the 14-3-3 protein for the diagnosis of sporadic Creutzfeldt-Jakob disease". Archives of Neurology. 60 (6): 813-6.
Chitravas N, Jung RS, Kofskey DM, Blevins JE, Gambetti P, Leigh RJ, Cohen ML (2011). "Treatable neurological disorders misdiagnosed as Creutzfeldt-Jakob disease". Annals of Neurology. 70 (3): 437-44.

Sano K, Satoh K, Atarashi R, Takashima H, Iwasaki Y, Yoshida M, Sanjo N, Murai H, Mizusawa H, Schmitz M, Zerr I, Kim YS, Nishida N (2013-01-25). "Early detection of abnormal prion protein in genetic human prion diseases now possible using real-time QUIC assay". PLOS ONE. 8 (1): e54915.

Foutz A, Appleby BS, Hamlin C, Liu X, Yang S, Cohen Y, Chen W, Blevins J, Fausett C, Wang H, Gambetti P, Zhang S, Hughson A, Tatsuoka C, Schonberger LB, Cohen ML, Caughey B, Safar JG (2017). "Diagnostic and prognostic value of human prion detection in cerebrospinal fluid". Annals of Neurology. 81 (1): 79-92.

Bongianni M, Orrù C, Groveman BR, Sacchetto L, Fiorini M, Tonoli G, Triva G, Capaldi S, Testi S, Ferrari S, Cagnin A, Ladogana A, Poleggi A, Colaizzo E, Tiple D, Vaianella L, Castriciano S, Marchioni D, Hughson AG, Imperiale D, Cattaruzza T, Fabrizi GM, Pocchiari M, Monaco S, Caughey B, Zanusso G (February 2017). "Diagnosis of Human Prion Disease Using Real-Time Quaking-Induced Conversion Testing of Olfactory Mucosa and Cerebrospinal Fluid Samples". JAMA Neurology. 74 (2): 155162.

Sanchez-Juan P, Green A, Ladogana A, Cuadrado-Corrales N, Sáanchez-Valle R, Mitrováa E, Stoeck K, Sklaviadis T, Kulczycki J, Hess K, Bodemer M, Slivarichová D, Saiz A, Calero M, Ingrosso L, Knight R, Janssens AC, van Duijn CM, Zerr I (August 2006). "CSF tests in the differential diagnosis of Creutzfeldt-Jakob disease". Neurology. 67 (4): 637-43.

Tattum MH, Jones S, Pal S, Khalili-Shirazi A, Collinge J, Jackson GS (December 
2010). "A highly sensitive immunoassay for the detection of prion-infected material in whole human blood without the use of proteinase K" (PDF). Transfusion. 50(12): 2619-27.

http://www.prionalliance.org/wpcontent/upload s/2013/11/prnp-prp-prion.png
Soto, C. Diagnosing prion diseases: needs, challenges and hopes. Nat Rev Microbiol 2, 809-819 (2004).https://doi.org/10.1038/nrmicro1 $\underline{003}$ 